\title{
LA PENicilinoterapia eN LA GONOCOCCIA INFANTIL
}

Tratamiento ambulatorio de la gonococcia infantil con penicilina inyectable.

(Estudio comparativo entre el suministro de la droga por via oral y for vía injestable).

Por el Prof. Dr. ALFREDO WIEDERHOLd y Dra, ANTONIETA MENDEZ

A mediados del año pasado presentamos un trabajo titulado "Tratamiento ambulatorio de la Gonccoccia Infantil con Penicilina por vía oral".

En csa exposición anotames 10 siguiente: de 25 enfermi. tos tratados con la drcga por vía bucal, que fueron observados por un período superior a 6 meses y sometidos a una enérgíca reactivición con protargel y nee-gynergeno, todos llegaten a la curación tanto bacteriológica ccmo clínica.

En esa ocasión, por los resultados obtenidos, pudimos deducir que la penicilina suministrada por vía oral, se absorbe y elimina en cantidad suficiente y en forma rápida, que no hay necesidad de mantener una penicilemia uniforme y constante y que bautan pequeñas descargas repetidas de la drcga por la ori. na, para destruir el gonoccco de Neisser.

Por estas razones, creemos que el tratamiento de la gonococcia infantil con penicilina, suministrada per vía bucal, es perfectamente viable y su resultado es favorable, siendo sólo cuentión de dosis.

La simplificación que trae su uso, sin los inconvenientes ni las molextias de las inyeccicnes y porque garantiza más efectivamente el secreto profesional. son causas suficientes para que este tratamiento merezca la consideración de los colegas en la práctica de su profesión. 
En la exposición anterior ya mencionamos la experiencia actual con penicilina inyectable, que habiamos iniciado en ese entonces.

Tomarnos 26 casos, los últimos de lcs cuales tienen un período de observación superior a 8 meses y los primeros casos tratados están bajo un control superior a un añe. Usamos la sal sódica en suspensión de aceite de oliva.

Con el deseo de hacer un estudio comparativo, vamos a mostrar el cuadro que sigue:

Penicilina por vis oral penicilina lenta oleosa

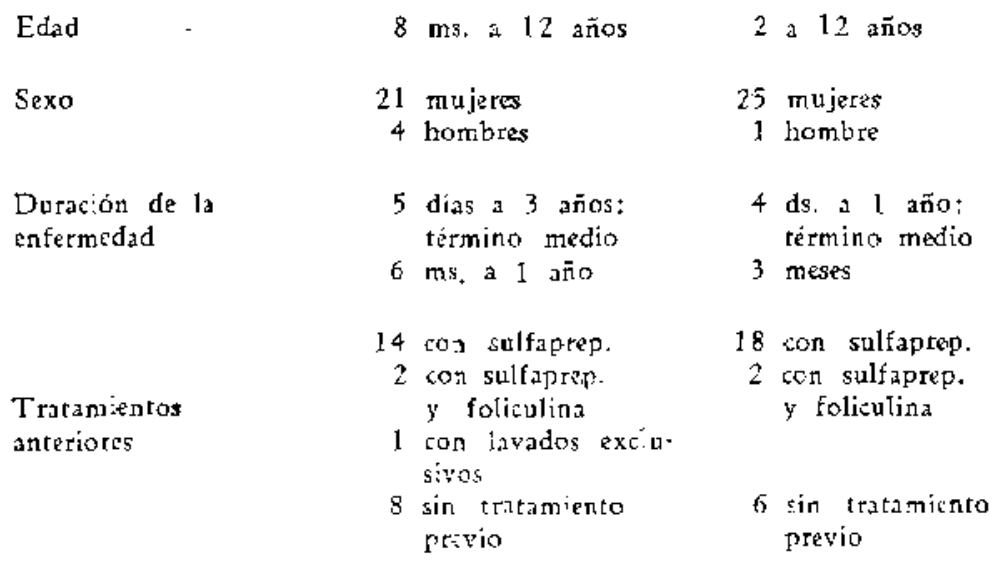

Como puede verse, el conjunto de niñes tratados por ambas vías șe presta bastante para hacer comparaciones.

Mocio de proceder. - En todos los casos efectuamos previamenti. un examen bactericlógico.de la secreción uretral o vulvovaginal y sometimos a tratamiento los que eran francamente positivos y con abundantz secreción purulenta.

Doxifiración de la penicilina. - A1 emplear la vía bucal, de scuerdo con algunos autores, usamos dosis 6 vetes superior a la inyectable (en la mayoría de los cases 300 a 600 'mil L.).

En el trabajo presente empezamos a usar, por inyecrión. $100 \mathrm{mil}$ U. pero esta desis debimos después aumentarla en los enfermos en que persistió la secreción y los frotes resultaron positivos. 
Al emplear la vía inyectable, usamos:

En 3 casos: $100 \mathrm{mil} \mathrm{U}$. en 2 inyeccicnes de $50 \mathrm{mil} \mathrm{U}$. cada 24 horas.

En 16 casos: 100 mil U. en una sola inyección.

En 2 casos: 150 mil U.

En 4 casos: 200 mil U.

En 1 caso: 250 mil. U.

La penicilina lenta oleosa por vía inyectable, la mandamos preparar en los laboratorios farmacéuticos. Usamos 1a penicilina-sódica que se emplea para la inyección corriente y cuya solución es acuosa. Como esa droga la inyectamos dentro de las 48 horas después de preparada, considerames que se podria recurrir perfectamente a la sustancia sódica.

Las 100,000 U. se suspendían en $2 \mathrm{cc}$. de aceite de oliva y a continuación se esterilizaba.

Per la experiencia adquirida en nuestro trabajo anterior, supimos que para destruir el gonococo de Neisser bastaban los golpes penicilínicos y no era necesario mantener en el pacierte una penicilemia uniforme y constante. Era ésta la razón por la cual recurrimos al aceite de oliva para suspender en él la droga. No nos importaba, por lo tanto. que este reticulo se absorbiera más rápidamente que el aceite de maní con cera de abejas. Nunca observamos en nuestros pacientes la formación de algún absceso por infección del aceite-retículo de la penicilina sódica.

Veintiuno de estos enfermos sanaron clínica y bacteriológicamente; los 5 restantes, los que recibieron más alta dosis, siguieron presentando frotes positivos al gonococo y abundante secreción purulenta $y$ al no obtener resultado con el aumentó de la dosis, los sometimos a la terapéutica por la via oral, con la cual obtuvimos una completa mejoría bacteriológica y clínica.

Reactivación. - Por la experiencia adquirida en nuestro trabajo anterior, también recurrimos a la reactivación en nuestros enfermitos. En esa ocasión dijimos que la reactivación fisiológica más intensa que se conoce es la menstruación. El sarampión. como enfermedad catarral, nos reactivó 2 casos. Empleamos, para hacer una reactivación artificial. instilaciones de protargol al $10 \%$. Impuestos en esa ocasión del uso de neo-gynergeno como el más enérgico de las sustancias reactivadoras. usamos esta droga. No nos extenderemos mayormente sobre ella, porque en el trabajo anterior 
han quedado expuestas ya en forma detallada, sus cualidades clínicas y farmacológicas. Nuestra experiencia nos demostró que en realidad es un reactivador artificial muy enérgico $\mathrm{y}$, por le tanto, acordamos emplearlo en forma exclusiva en el trabajo presente, en la forma y dosis ya indicadas en nuestra exposición anterior.

Consideramos entonces, que un enfermito reactivado con neo-gynergeno y cuyos resultados indiquen una negati. vidad absoluta bacteriológica a repetición de la secreción vulve-vaginal o uretral, podemos considerarle prácticamente curado da su gonococcia. Nos bastamos para sostener estos principios en la observación bastante prolongada de los niños de nuestro trabajo anterior, que han sido conttolados algunos por más de 2 años y la mayoría por un período superict a 1 año. Agregamos a ello lcs casos observados en la presente experiencia, que como dijímos, están controlados por más de 8 meses algunos, y otros, por más de 1 año. Todos estor pacientes sometidos a la penicilinoterapia suman 63 casos.

De los pacientes tratados con penicilina por vía orai. hasta la fecha ninguno ha presentado una recaída de su afección gonocócica. Sólo nos ha llamado la atención un hecho: 3 de estcs enfermitos tuvieron después una secreción purulenta más o menos acentuada; pero cuyo examèn bacteriológico repetido fue negativo para el gonococo de Neisser. Consideramos estas vulvovaginitis como debidas a infeccicnes secundarias, que se implantan con mayor facilidad sobre estcs órgancs previamente lesionados por la infección gonocócica.

Tratamos estas infecciones banales con instilaciones $d$ ? nitrato de plata al 1 x 5,000, con lo cual se consiguió $1_{a}$ desaparición de la secreción.

Exfosición comparativa entre la terapéutica de la gonorrea infantil - con penicilina por via cral y con penicilina por vía ingectable.

Antes de entrar en los detalles, queriamos referimos al trabajo que publicó el cirujano suizo Prof. A. Brunner, de la Clínica Universitaria de Zurich. Articulo: "Posibilidades y límites de la Penilicinoterapia en Cirugía", que apareció en el "Schweizerische Medizinische Wochenschrift", de 3 de mayo de 1947, dicé

"Desgraciadamente la terapéntica penicilínica oral ha fallado aún con una dosificación 5 veces superior a la vía 
inyectable $y$ con suficientes preparados tampón para neutralizar el ácido clorbídrico gástrico, exceptó en lactantes y en infecciones de las vías urinarias sin la uretra.

"En los lactantes, en los primeros meses de la vida, tegún Enderson y Mac Adam, es aún superior a la terapéutica por vî́a inyectable. En las infecciones de las vías urinarias rara vez se recurre a la penicilina vía oral, porque generalmente intervienen en ellas el bacilo coli y el enterococo".

De los 25 pacientes tratados en forma ambulatoria con penicilina por vía oral, todos sanaron con dosis que oscilaban entre 200,000 y $1.500,000 \mathrm{U}$. La mayoría de ellas tratadas con dosis de 300 y $600,000 \mathrm{U}$. Dijimos en esa ccasión que sólo era cuestión de dosis y que hasta entonces no se habian encontrado casos penicilino-resistentes.

Que esa terapéutica tenía las ventajas expuestas ya al comienzo de este trabajo, que sólo se usaba mayor dosis, coia que en realidad no desempeñaba un rol importante en Ia actualidad, porque no hay esasez de la droga en el comercio y es réativamente barata.

Al usar la vía inyectable, necesitamos dosis menores de 100 a 200 a 250 mil U., pero algunos de los casos no sanaron con este tratamiento y sí punteriormente con la terapéutica per vía oral.

N-: deceamos abanderizarnos a una de estas terapéuticas detcrminadas, sino únicamente queremos exponer a los colegas un métcdo más como es e! de la vía oral, para tratar esta enfermedad infantil, el cual, por lo menos, es tan aficaz ccmo el de la vía inyectable y tiene las ventajas ya enunciadas.

Cremos que los colegas pedrán recurrir a uno u otro de loy procedimientos. según las indicaciones, según las circunstancias y según las condiciones en las cuales debar actuar y esto se dejará al criterio de cada cual.

\section{Summary.}

The authers presents a $n \in w$ series of children aficted from genococcic infection treated with penicilin by cral administration. 